\title{
Thanatophoric dysplasia, an enigmatic dilemma: a case report
}

\author{
Chanda Rai $^{1 *}$, Harsha Shailesh Gaikwad ${ }^{1}$, Sunil Kumar Bajaj ${ }^{2}$, Rohini Gupta ${ }^{2}$
}

${ }^{1}$ Department of Obstetrics and Gynaecology, ${ }^{2}$ Department of Radiology, VMMC and Safdarjung Hospital, New Delhi, India

Received: 08 November 2015

Revised: 06 June 2016

Accepted: 09 July 2016

*Correspondence:

Dr. Chanda Rai,

E-mail: chanda17.rims@gmail.com

Copyright: () the author(s), publisher and licensee Medip Academy. This is an open-access article distributed under the terms of the Creative Commons Attribution Non-Commercial License, which permits unrestricted non-commercial use, distribution, and reproduction in any medium, provided the original work is properly cited.

\begin{abstract}
Thanatophoric dysplasia is a rare, fatal form of skeletal dysplasia that affects fetus in utero. It is characterized by marked underdevelopment of fetal skeleton and short limbs. This disorder can be diagnosed antenatally and the couple should be counselled for termination of pregnancy. 20 years old female came in her second trimester carrying an ultrasound report which showed features of thanatophoric dwarfism. She was advised to terminate her pregnancy but she decided to continue with her pregnancy. She was induced after 40 weeks and she delivered a stillborn baby with dwarf like features, a condition identified as thanatophoric dwarfism. Early diagnosis can be done by ultrasound as early as 13 weeks of gestation and since babies born with thanatophoric dysplasia have a very poor prognosis, couples should be counselled regarding early termination of pregnancy. 3D ultrasound scan and molecular analysis can also help identify this disorder.
\end{abstract}

Keywords: Dysplasia, Skeleton, Pregnancy

\section{INTRODUCTION}

Thanatophoric dysplasia (TD) is a form of skeletal dysplasia with very few isolated cases all over the world. It is the second most lethal form of skeletal dysplasia after osteogenesis imperfecta type 2. The word thanatophoric is Greek for "death bearing" or "death bringing". It is rare with an estimated incidence of 0.28 to 0.60 per 1000 births. ${ }^{1}$ Very few cases of thanatophoric dysplasia have been reported from India so far. This condition is characterized by marked underdevelopment of the skeleton and short limb dwarfism. ${ }^{2}$ Phenotypically, these infants have macrocephaly, platyspondy or flattened vertebral bones, narrow thoracic cage with hypoplastic lung, normal trunk length and rhizomelia or severe shortening of limbs. This condition usually leads to death in neonatal period from respiratory insufficiency. We report one such case of thanatophoric dyspasia here.

\section{CASE REPORT}

20 years old patient came to our OPD as primigravida at 16 weeks of pregnancy citing some abnormality in the fetus in her ultrasound report. Her level 2 ultrasound report showed femur length of $10 \mathrm{~mm}$ suggestive of skeletal dysplasia. She was counselled regarding termination of pregnancy owing to poor fetal prognosis but the couple wished to continue her pregnancy. There was no history of similar or any other type of malformations in fetus in any of the family members. An MRI was done which showed a large fetal skull with indentations on both sides giving appearance of clover leaf shaped skull (BPD- $96 \mathrm{~cm} \sim 39$ weeks 2 days) with normal brain parenchyma and ventricular system. Fetal neck appeared short with hyper-extended fetal head giving star gazing appearance. Thoracic cavity was small and narrow. Bilateral humerus and femori were extremely short $\sim 22 \mathrm{~mm}$ and $19 \mathrm{~mm}$, corresponding to 5 weeks 6 days, respectively with metaphyseal flaring. Other bones 
like radius, ulna, tibia and fibula were also very short. Pelvis was narrow with small, squared iliac wings. Diffuse skin and subcutaneous soft tissue was thickened. Liquor was found to be increased. Fetal spine was normal.

Since patient was not willing for termination, she was kept in follow-up for the rest of her pregnancy. Her labour was induced at 40 weeks 3 days and had she vaginal breech delivery of a stillborn male fetus, weighing $2.5 \mathrm{~kg}$, who died during the course of labor (Figure 1). The couple did not agree for the autopsy of the fetus. However, an infantogram of the fetus could not be taken post-delivery (Figure 2).

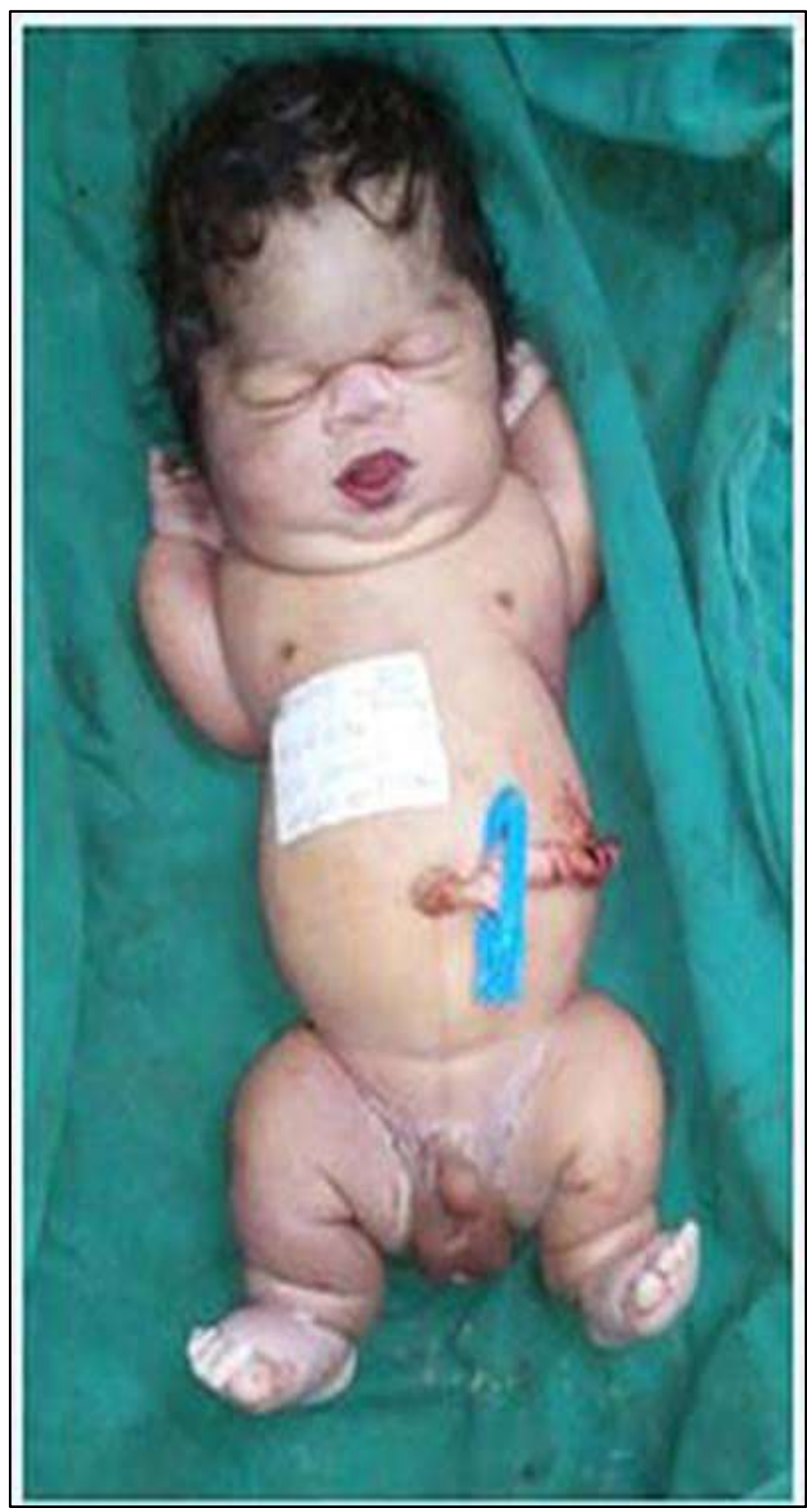

Figure 1: The picture of the male baby shows a large head with bulging forehead, flattened nasal bridge, short neck, long trunk with very short limbs with redundant skin folds.

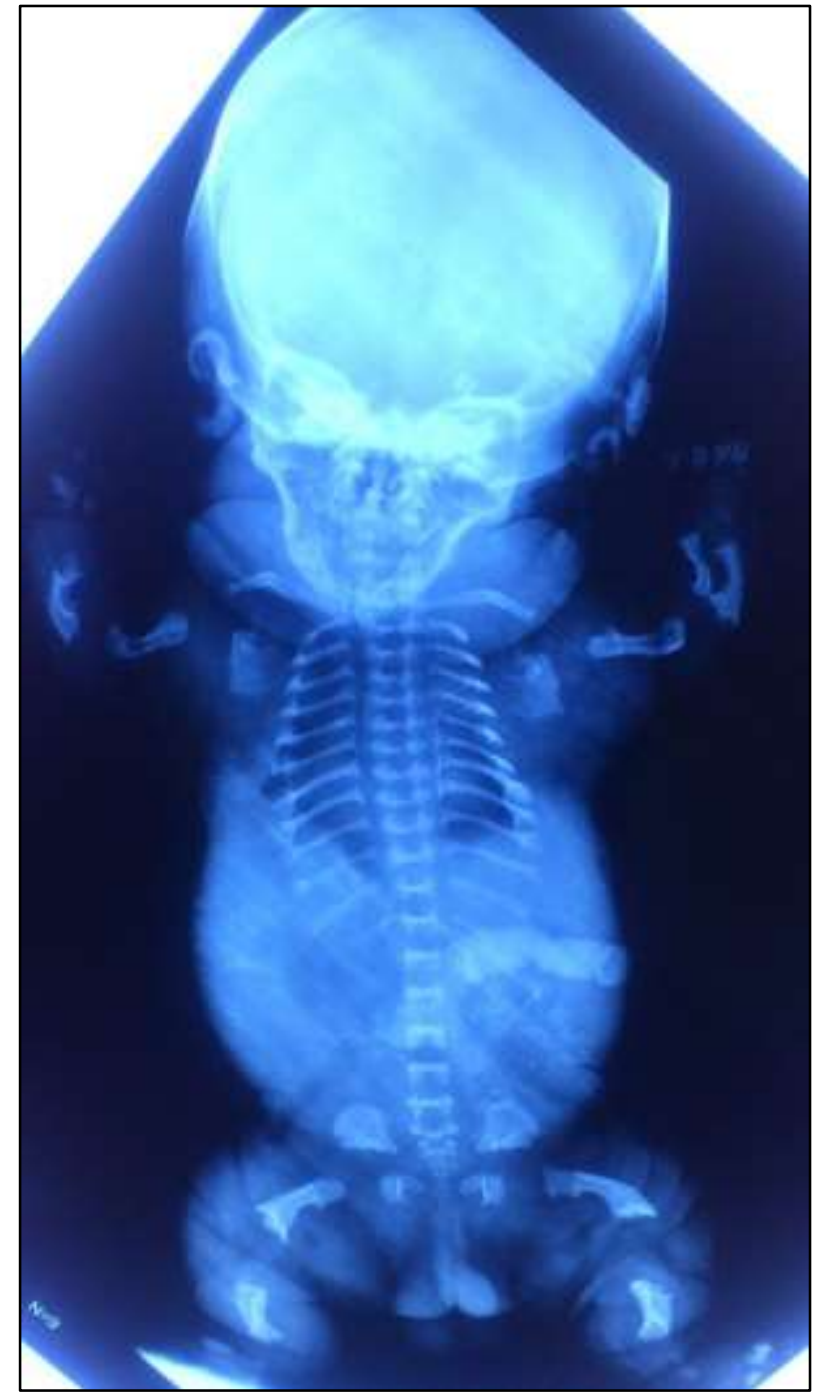

Figure 2: An infantogram was done which showed a large calvarium with narrow thoracic cavity and shortened ribs with anterior splaying, flattened vertebral bodies (platyspondyly), squared iliac wings or which mimic "elephant ears" and short bowed femurs giving "telephone receiver "appearance

\section{DISCUSSION}

TD is an autosomal dominant disorder caused by missense mutation in Fibroblast growth factor receptor 3 or FGFR 3. All cases of TD are due to new mutations and due to its sporadic nature, incidence is less than 3\%.This condition was first brought to notice by Montreaux et al in $1967 .{ }^{3}$ The gene is present on the short arm of chromosome 4 (4p16.3). FGFR3 belongs to tyrosine kinase receptor family which acts as negative regulator of bone growth. Point mutation occurs in FGFR 3 gene in cases of thanatophoric dwarfism which prevents chondrocyte differentiation leading to disorganised endochondral ossification at bone growth plate. Risk of recurrence is less than $5 \%$, possibly caused by gonadal mosaicism. Of the two types of TD, type 1 constitute fetuses with short curved limbs giving telephone-receiver 
appearance with macrocephaly but normal shaped skull, as seen in our case while type 2 is associated with clover leaf shaped skull and straight femur bone.

Diagnosis is made by ultrasound done in second or third trimester which include the following radiological features:

- Macrocephaly or clover leaf shaped skull or "kleblattschaedel"

- Rhizomelia viz. short, bowed bones esp. of femur

- Narrow rib cage with short, splayed, cupped ribs

- Platyspondyly or flattened 'U- shaped' vertebral bones

- Redundant soft tissues of limbs

- Squared iliac bones

- Normal trunk length.

\section{Polyhydramnios is commonly associated}

On 3-D ultrasound, features like skin thickening and cranio-facial abnormalities are seen.

MRI can help visualize narrow foramen magnum and platyspondyly, Differential diagnosis includes osteogenesis imperfecta types 2 and 3, achondroplasia, achondrogenesis.

Prognosis is poor as death occurs mostly due to respiratory failure owing to hypoplastic lungs or from brainstem compression from narrowed foramen magnum. ${ }^{4}$ However hence, if the condition is diagnosed pre- natally couples should receive genetic counseling and advised for termination of pregnancy. Without proper counseling, families who had a previous child affected with thanatophoric dysplasia would be anxious to think of a future pregnancy. ${ }^{5}$ If the diagnosis is made after the birth of the baby, management is solely supportive, as death occurs from respiratory insufficiency within hours to days.

Thanatophoric dysplasia, although rare, is a lethal disorder of fetus and can be detected by ultrasound done in second trimester. Early diagnosis helps in prognostication and termination can be offered to the patients.

Stress should be laid upon proper genetic counseling as couples tend to get anxious about recurrence of this disorder in future pregnancies. Couples should be assured about chances of a normal pregnancy because of the sporadic nature and low risk of recurrence of this disorder. An ultrasound scan can rule out any form of skeletal disorder or any other fetal abnormality in early pregnancy. It is possible to recognize short limbs in fetuses beginning as early as 13 weeks of gestation when femur length can be routinely assessed. ${ }^{6}$ 3-D anatomy scan and amniocentesis for molecular analysis can detect the disorder in the second trimester and in case of this abnormality, termination should be advised.

\section{Funding: No funding sources \\ Conflict of interest: None declared \\ Ethical approval: Not required}

\section{REFERENCES}

1. Corsello G, Marasi E, Rossi C, Giuffre L, Cittadini E. Thanatophoric dysplasia in monozygotic twins discordant for clover leaf skull: prenatal diagnosis, clinical and pathological findings. Am J Med Genet. 1992;42:122-6.

2. Naveen NS, Murlimanju BV, Kumar V, Pulakunta T, Jeeyar H. Thanatophoric dysplasia: a rare entity. Oman Medical Journal. 2011;26(3):196-7.

3. Maroteaux P, Lamy M, Robert JM. Thanatophoric dwarfism. Presse Med. 1967;75:2519-24.

4. Lam AC, Lam YY, Tong TM, Chan DK, Lau WL, $\mathrm{Ng} \mathrm{Dk}$, et al. Thanatophoric dysplasia type1 without telephone receivers. HKJ Paediatr. 2006;11:320-3.

5. Mac Donald IM, Hunter AG, MacLeod PM, MacMurray SB. Growth and development in thanatophoric dysplasia. American Journal of Medical Genetics. 1989;33:508-12.

6. Pretorius DH, Rumack CM, Manco- Johnson ML, Manchester D, Meier P, Bramble J, et al. Specific skeletal dysplasias in utero: Sonographic diagnosis. Radiology, 1986;159:237-42.

Cite this article as: Rai C, Gaikwad HS, Bajaj SK, Gupta R. Thanatophoric dysplasia, an enigmatic dilemma: a case report. Int J Reprod Contracept Obstet Gynecol 2016;5:2856-8. 